\title{
RESEARCH INFO "BULLWHIP EFFECT"IN SUPPLY CHAIN MANAGEMENT SYSTEM BASED ON WSRF IN GRID
}

\author{
Yan Kang, Shiying Kang \\ Institute of Computer Science and Information Engineering,Chongqing Technology and \\ Business University, Chongqing, China;Email:kangsy@ctbu.edu.cn
}

\begin{abstract}
Strengthening the information share extent and establishing the supply chain resources share system based on network is the important measure to weaken "bullwhip effect". The reason that causes the low efficiency for supply chain information share platform based on traditional Internet and Web Services to weaken "bullwhip effect" is expounded. Through the analysis on supply chain management platform designed with the WSRF.NET technology in Grid environment, the effect of the platform on reducing "bullwhip effect" is also demonstrated theoretically and technologically.
\end{abstract}

Key words: Grid; WSRF (Web Service Resource Framework); Supply Chain Management; Bullwhip Effect.

\section{INTRODUCTION}

"The Bullwhip Effect" is the phenomenon that the change extent of the order quantity that was from lower reaches to upper reaches of supply chain increase step-by-step, or even greatly contort. It is a hot issue that is focused by supply chain enterprises and their managers. To "the Bullwhip Effect", many scholars have done their research. The famous "Beer game"[1] carried out by Steman of Sloan School of Management in the American Massachusetts Institute of Technology is the research model on Bullwhip Effect, which is based on the system dynamics. This experiment shows that in the linearity cost structure, the order quantity increases when it moves to the upper reaches of the supply chain. Because the information is delayed,

Please use the following format when citing this chapter:

Kang, Yan, Kang, Shiying, 2006, in International Federation for Information Processing (IFIP), Volume 207, Knowledge Enterprise: Intelligent Strategies In Product Design, Manufacturing, and Management, eds. K. Wang, Kovacs G., Wozny M., Fang M., (Boston: Springer), pp. 344-349. 
order form will not reflect the present practical beer demand, and it is difficult for the decider to forecast the demand. Researchers of this experiment believe that the Bullwhip Effect in supply chain system is decided by the structure of this system. System structure affects every part's behavior in system, so the appearance of Bullwhip Effect is inevitable.

Nowadays, to weaken "the Bullwhip Effect" by setting up Internet supply chain share system has become the common understanding of many domestic and foreign scholars. Especially the system which is open, can well combine with information system of every enterprise in supply chain, and can make every enterprise smoothly and perfectly realize the direct information communication and resource communication, is the ideal system in people's heart. So, we can find out that the problem through realization of information share and supply chain system structure change to weaken "The Bullwhip Effect" has been solved. However, the practice in recent years cannot be all that could be desired, which is showed in the following facts.

\section{REDUCTION OF "THE BULLWHIP EFFECT" THROUGH SUPPLY CHAIN INFORMATION SHARE SYSTEM ON TRADITION INTERNET}

In recent years, scholars are devoted to set up supply chain information resource share system on traditional Internet. The presented system can be divided into two kinds: (1) Supply chain information share system based on Internet, (2) Supply chain information share system based on Web Service

\subsection{Supply chain share system based on Internet}

In 2002, Gong Bengang put forward a information share system model based on Internet; Pan Yigang et al further put forward the technology for setting up supply chain management system applied XML and SOAP technology on Internet], to provide interface for different manufacturers on different platforms of supply chain members, so that the reduction of "The Bullwhip Effect" through information share in supply chain is realized. But this method doesn't work well; because:(1)Different software in asynchronous platform actually doesn't have a uniform description language and uniform format. Uniform information transfer cannot be realized among platforms.(2) Concurrency Control and asynchronous control in information transfer can not be solved. We can see that though an information share system has been connected in Internet form, actually information share is hard to realize. So the reduction of "Bullwhip Effect" is very limited. 


\subsection{Supply chain share system based on Web Service}

The appearance of Web services that are open and span-platform realizes a good mechanism for supply chain to set up asynchronous platform information system and "share resource". In 2002 Xu Wei et al present "the workflow technology integrate in logistics based on Web Service"[4], and from 2004 to 2005, Xian Feng, Jin Jiwen et al carried out the supply chain system research and realization based on Web Services, and the supply chain information share is made great progress.

But supply chain doesn't realize the real "resource share" in technology, because:(1) Many important "Non share part" resources which are closely relevant to supply chain separately distribute on every network website, they cannot be effectively found and used. "Information isolated island" and "resource isolated island" cannot be removed. (2) The speed and efficiency of Web services are always severely restricted by non-share software or hardware and network, and even long time wait or computer system crash happens. (3) What the especially serious situation is that when the connected software and hardware are too many, every enterprise information system of every supply chain can not be well combined, or either information communication and resource communication can smoothly carried out. Now we can see that though the theoretical research on "Bullwhip Effect" has achieved great progress, when Grid isn't referred, any effort for people to apply share platform to reduce "Bullwhip effect" fails to meet the demand.

\section{REDUCTION OF SUPPLY CHAIN PLATFORM ON BULLWHIP EFFECT BASED ON WSRF}

Grid brings new hope for supply chain share platform that can truly reduce "The Bullwhip Effect". But the building process is tough and hard.

\subsection{Web Service based on Grid}

Grid is a new technology constructed in the new generation Internet. It will combine high speed Internet, PC of different geography locations, high capability computer, large database, sense organ, long distance equipment, peripheral equipment and so on together, so the whole Internet becomes a huge super computer that is comparatively transparent to clients. The resource share and cooperation among computer resource, storage resource, communication resource, software resource, information resource, knowledge resource and so on are realized, and information isolated island and resource isolated island are eliminated. 
Since both the Grid and Web Services have such advantages, it is natural for people to consider bringing Web Service in Grid. "Web Service based on Grid"-Grid Service is formed to realize the combination of Grid and Web Service. So through Grid, every application and resource on "asynchronous structure" network is connected. "Huge super computer" is formed. It not only solves the "bottleneck" problem of speed and efficiency of Web service, but also provides every kind of resource for the whole Grid. So in the recent 1 or 2 years, the supply chain information share system based on Grid technology is put forward.

\subsection{The presentation of supply chain information share system based on Grid technology}

In 2003, Liu Wei et al put forward the assumption of "supply chain management system based on Grid calculation"; Zhao Xinjuan et al put forward the "supply chain management system model based on Grid calculation" and the concept of "based on facing to grid service".

However at that time, Grid and Web Services were not truly combined in technology. The former Grid system structure based on the OGSA/OGSI (Open Grid Service Architecture/Open Grid Service Infrastructure) that has some shortages and disadvantages: (1) The criterion and explanation are too complicated to support the future extension and development; (2) When used, serious problems exist among OGSI and the present Web service, WML tool, and the expansion of WSDL is difficult; (3) The concept and method of "face to object" are over used. These shortages form a certain obstacle to prevent the further development of Grid technology. Every grand computer company of the whole world puzzles its brain about how to make full use of the advantages of Grid and Web Services. The research on the combination of Grid and Web Services is on the initial stage.

\subsection{Reduction influence of supply chain management platform based on WSRF on the Bullwhip Effect}

The real combination of Grid and Web Service was after IBM, Globus union and HP put forward the WSRF in 2004. 


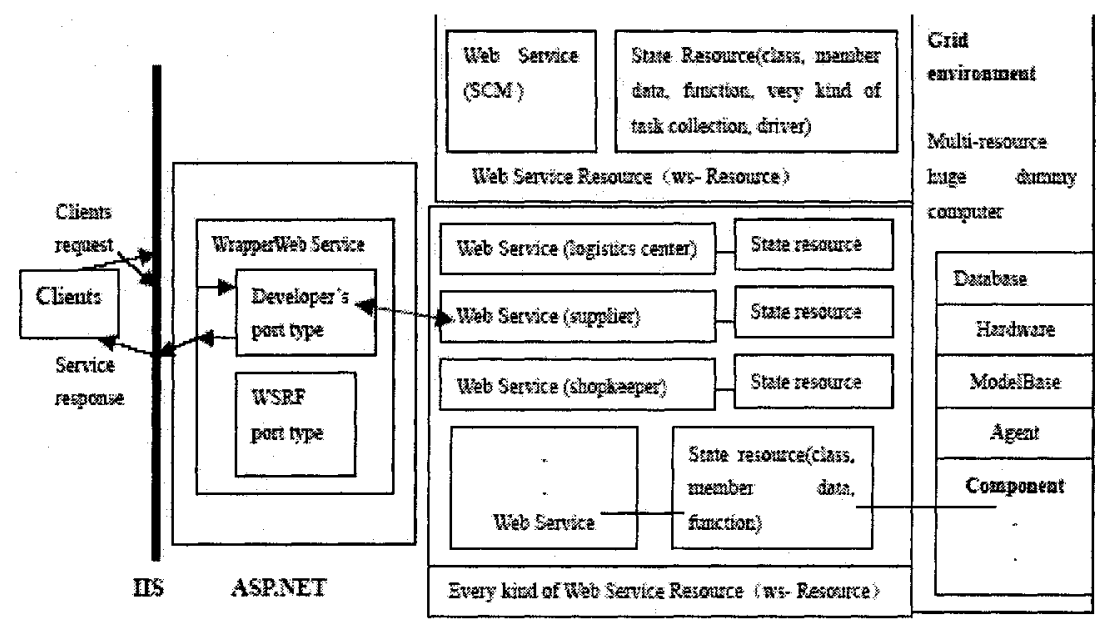

Figure 1. Supply Chain Management platform Model based on WSRF in grid

WSRF is a new method to express the relation between Web Service and state resource, and is the realization of combination of Grid technology and Web Service. It adopts different structures to modeling state resource and its related Web Service, while OGSI adopts one structure to modeling one state resource as one Web Service. Only one to one mapping relationship is allowed between Web Service and its related state resource in OGSI. WSRF can form many to many mapping relationship. So as a interface and management technology of calling WS-Resource, WSRF replace OGSI to provide the realization conditions for the supply chain information share system to achieve real resource share and cooperation, and to get rid of information isolated island and resource isolated island.

Figure 1 is the Model of the supply chain management platform that is designed through applying WSRF.NET2.0, and using related distributed system based on WSRF.NET technology for reference by us [9].

In this platform, the "Wrapper Web Service" is generated by WSRF.NET service (ASP.NET service) tooling. This Service is from the web service written by service developer port types and certain WSRF specificationdefined port types that the developer chooses to include. This Service can run as a normal Web Service in ASP.NET worker process. IIS dispatches HTTP requests to the service, which internally invokes either a method on a port type written by service developer or a port type defined by WSRF.

Before the method is invoked. The Wrapper Web Service uses the value of the EPR (EndpointReference) in the $<$ To $>$ header of the invocation SOAP message to interact with a particular WS-Resource and retrieve state values. 
WSRF.NET automatically resolves the execution context presented in the EPR and provides a programmatic interface to access the specified WSResource (class, member data, function, every kind of task collection, driver and so on). Although there are many different resolution mechanisms and types of WS-Resource, WSRF.NET implements WS-Resource by executing method on developer's port type or WSRF port type. These methods include visiting database, driving hardware and processing information for every Web service and client side.

WSRF.NET2.0 can provide interface for developer to design the function he needs, and can carry through the building, producing, loading, storing and so on of every kind of WS-resource" [9][10][11]]. So this platform can use WSRF to integrate every member heterogeneous information system in supply chain, and to realize the share of smoothly direct information communication and resource communication and every software and hardware support platform; meanwhile, recurring to Grid technology environment, high capability resource can be chosen to meet the special demand of clients in high speed and efficiency (such as decision-making analysis, high speed calculation, intelligent calculation, and high speed flow media transfer). So not only the "information isolated island" and "resource isolated island" phenomenon can be eliminated, but also every enterprise member in supply chain can make use of technology condition to set up close cooperation between each other in supply chain.

The appearance of WSRF is the sign that the Web Service integration technology based on Grid has developed to a new stage. From this stage on, supply chain management platform can possess the realization conditions to realize the information share and resource share span time and space in technology.

\section{REFERENCES}

1 Sterman J D. The beer distribution game [A]. In Heieke J, Meile L, Eds. Games and Exercises for Operations Management [M] . New Jersey: Prentice Hall, (1995). 101-112

2. Wei Xu, Zong-Kai Yang, Jing Xia, Application of Workflow Based on Web Services in Logistics System Integration [J, Logistics Technology, (2002).2:16:19

3. Wei Liu, Supply Chain Management System based on Grid Computing [J], Group Technology and Production Modernization Vol.20, No.3 (2003):28-31

4. Xin-juan Zhao, Guo-zhen Tan, Xun-y IJ Wang, Research on the Model of Supply Chain Management System Based on Grid Computing [J], May (2004):82-84

5. Glenn Wasson,Marty Humphrey, Exploiting WSRF and WSRF.NET for Remote Job Execution in Grid, Appears in the Proceedings of the 19th IEEE International Parallel and Distributed Processing Symposium(IPDPS 2005).April 3-8.2005.Denver.CO.

6. WSRF.NET 2.0 Programmer's Reference

7. WSRF.NET Developer Tutorial 